\title{
O MODO DE ENTENDER E FAZER A EDUCAÇÃO: O PROFESSOR FRENTE À FORMAÇÃO CRÍTICO-REFLEXIVA NA EDUCAÇÃO SUPERIOR
}

\author{
Carmen Lúcia Dias ${ }^{1}$, Aidê de Melo Alves ${ }^{2}$, Alessandra Tiemi Ynoue ${ }^{2}$, Célia dos Santos Silva ${ }^{2}$ \\ ${ }^{1}$ Docente do Curso de Mestrado em Educação da UNOESTE. ${ }^{2}$ Discente do Curso de Mestrado em Educação da UNOESTE
}

\begin{abstract}
RESUMO
Este artigo de revisão bibliográfica, tem por objetivo propor uma reflexão sobre posturas do professor do Ensino Superior, favoráveis à formação de profissionais críticos-reflexivos. Dúvidas e preocupações surgem diante do compromisso que o professor deve assumir no processo ensino-aprendizagem, considerando as exigências para o desenvolvimento de atividades com alunos em sala de aula, acompanhado da tradição de um ensino historicamente empirista. Será que como profissionais formadores de opinião, com vista ao desenvolvimento da autonomia e a práticas emancipatórias, estão preparados para refletirem sobre suas ações, tomarem decisões, serem críticos e criativos diante dos desafios das atividades profissionais do dia a dia? A escola está envelhecida em seus métodos, procedimentos e currículos, se distanciando velozmente da sociedade e das demandas atuais. Por outro lado, o modelo de passar conteúdo e cobrar devolução é obsoleto. Não podemos dar tudo pronto no processo de ensino e aprendizagem; aprender exige envolverse, pesquisar, ir atrás, produzir novas sínteses, fruto de descobertas. Diante de tantas informações disponíveis, é importante para o educador encontrar a ponte motivadora para que o aluno desperte e saia do estado passivo, de espectador. Aprender hoje é buscar, comparar, pesquisar, produzir e comunicar. Portanto, para a formação de alunos e professores com senso crítico e indagadores, refletindo sobre as mudanças para este novo perfil, é preciso que se façam inovações para as universidades; que, ultrapassem os limites da previsibilidade e da burocracia, tornando-se uma organização significativa, desafiadora, inovadora e empreendedora.
\end{abstract}

Palavras-chave: formação crítico-reflexiva, educação superior, aprendizagem, formação de professores.

\section{HOW TO UNDERSTAND AND MAKE THE EDUCATION: THE TEACHER FACING THE CRITICAL- REFLEXIVE FORMATION IN HIGHER EDUCATION}

\begin{abstract}
This bibliographic article, aims to propose a reflection on teacher attitudes of Higher Education, in favor of the training of critical-reflexive professional. Questions and concerns arise in the presence of the commitment that the teacher should assume in teaching-learning process, considering the requirements for the development of activities with students in the classroom, associated to the tradition of an education historically empiricist. As professionals opinion makers, to develop autonomy and emancipatory practices, could they be prepared to reflect on their actions, make decisions, be creative and critical, facing challenges of the professional activities in everyday? The school is aged in his methods, procedures and curriculum, rapidly keeping away from society and current demands. On the other hand, the model of transmitting subjects and charge return is obsolete. We can't give everything ready in the process of teaching and learning; learning require to get involved, search, investigate, to produce new syntheses, the result of discoveries. Having so much available informations, it's important for the teacher find the motivating bridge for the student wake up and leave the passive state of viewer. Learning today is to investigate, compare, research, produce and communicate. Therefore, for the formation of teachers and students with critical thinking and inquiring, reflecting on the changes for this new profile, it's necessary to make innovations to the universities; which exceed the limits of predictability and bureaucracy, becoming a meaningful organization, challenging, innovative and entrepreneurial.
\end{abstract}

Keywords: critical-reflexive formation, higher education, learning, teachers' formation. 


\section{INTRODUÇÃO}

Dúvidas e preocupações surgem diante do compromisso que o professor deve assumir no processo ensino-aprendizagem, considerando as exigências para o desenvolvimento de atividades com alunos em sala de aula, acompanhado da tradição de um ensino historicamente empirista. Será que como profissionais formadores de opinião, com vistas ao desenvolvimento da autonomia e a práticas emancipatórias, estão preparados para refletirem sobre suas ações, tomarem decisões, serem críticos e criativos diante dos desafios das atividades profissionais do dia a dia?

O modo de entender e fazer a educação, a forma como ela é trabalhada em sala de aula, espaço de interação entre professores e alunos, é o que vai caracterizar, em grande parte, uma formação profissional no sentido progressista, crítico-reflexivo ou conservador e tecnicista (SORDI; BAGNATO, 1998).

A educação superior tem exigido professores não somente preparados para ministrar aulas e com a concepção de que para ensinar basta apenas dar aula sobre determinada disciplina, mas sim, professores como mediadores no processo de aprendizagem, incentivando e motivando o aprendiz para que este possa sentir-se responsável pela sua própria formação.

A escola está envelhecida em seus métodos, procedimentos e currículos, se distanciando velozmente da sociedade e das demandas atuais. Por outro lado, o modelo de passar conteúdo e cobrar devolução é obsoleto. Não podemos dar tudo pronto no processo de ensino e aprendizagem; aprender exige envolverse, pesquisar, ir atrás, produzir novas sínteses, fruto de descobertas.

Diante de tantas informações disponíveis, é importante para o educador encontrar a ponte motivadora para que o aluno desperte e saia do estado passivo, de espectador. Aprender hoje é buscar, comparar, pesquisar, produzir e comunicar. Portanto, a escola precisa re-aprender a ser uma organização efetivamente inovadora, significativa, empreendedora, com professores que surpreendam seus alunos, trazendo novidades, variando suas técnicas e métodos de organizar o processo de ensino-aprendizagem (MORAN, 2000), se adequando para uma formação profissional preconizada pelas diretrizes curriculares, buscando formar um profissional inovador, agente de transformação, para atender às necessidades reais da sociedade atual.

Essa idéia é referendada com o pensamento de Freitas (1995), que propõe uma formação crítico-reflexiva como competência para transformar a realidade social. Esta tem sido uma das metas e propostas da maioria das Instituições de Educação Superior, contudo, como nos alerta Sordi e Bagnato (1998, p. 85) "[...] é o modo de entender e fazer a educação, de como ela é trabalhada em sala de aula[...] ", o que irá determinar o tipo de formação.. Ainda das autoras, entendem que a formação educacional vai ocorrendo ao longo da vida, e nela, a sala de aula assume um papel de destaque nas atividades educativas, onde se constrói um espaço formal no qual ocorre o processo.

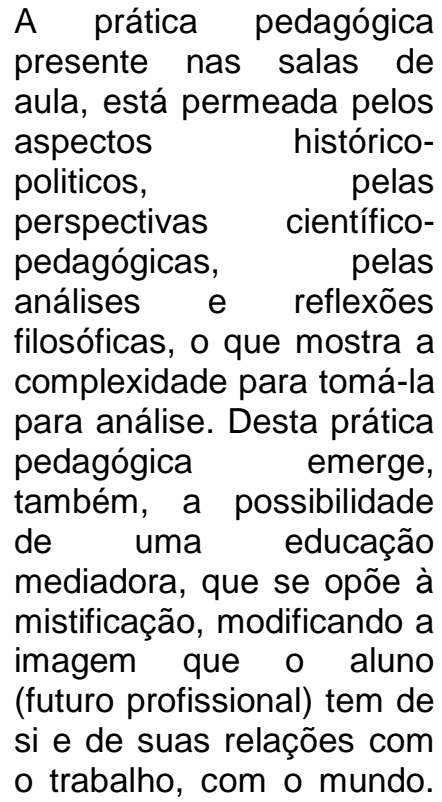


(SORDI; BAGNATO, 1998, p. 85).

Corroborando a idéia está Nóvoa (1991), quando afirma que a educação assume uma função mediadora de uma prática social, onde a metodologia de formação é aquela capaz de fazer o aluno compreender criticamente a prática social na qual vive $e$ em que vai interagir profissionalmente. Libâneo, vai além, quando fala do papel profissional dentro de uma sociedade que exige mudanças e transformações, portanto:

Há que se considerar, sem dúvida, a importância da formação teórica, de uma cultura crítica, e aqui já se apresenta um dos sentidos da reflexividade. A escola é um dos lugares específicos do desenvolvimento da razão, portanto, de desenvolvimento da reflexividade. [...] Mas, principalmente, a escola é lugar da formação da razão crítica através de uma cultura crítica, [...] que propicia a autonomia, auto derminação, condição de luta pela emancipação intelectual e social. [...] Se queremos um aluno crítico reflexivo, é preciso um professor crítico reflexivo. (LIBÂNEO, 2006, p. 76)

Com os novos tempos e com o desenvolvimento tecnológico, abrem-se canais para mudanças e transformações, que desconfiguram 0 papel do professor como detentor ou do que repassa o conhecimento e informações. É preciso diálogo, outras fontes de conhecimento e preocupação com pesquisas, em uma relação mais efetiva entre professor e aluno (MASETTO, 2003).

Daí a importância do pensamento crítico na formação do profissional de nível superior, com estratégias de ensino que além de buscar nos alunos suas experiências de vida, estimulem e provoquem nestes a necessidade de enfrentarem problemas presentes na vida cotidiana de trabalho, com novos requisitos de aprimoramento e critérios para ser considerado um profissional comprometido com a realidade social.

Para Litwin (2000, p. 194), os princípios orientadores de diversos estudiosos, coincidem em reconhecer uma cultura das práticas de ensino que privilegia o pensar em classe onde há expectativas postas à reflexão do aluno acompanhando o processo reflexivo do docente, e que "o ensino para a reflexão e o desenvolvimento do pensamento crítico é um ensino que cria nos contextos de prática as condições para esse tipo de pensamento".

Basendo-se nas considerações apontadas, o presente artigo constitui um estudo bibliográfico, tendo por objetivo propor uma reflexão sobre posturas do professor do Ensino Superior, favoráveis à formação de profissionais críticos-reflexivos.

A hipótese de trabalho apresenta-se de forma a considerar que a realidade das Instituições formadoras de Educação Superior, mesmo na perspectiva de uma formação críticoreflexiva, ainda tem muitos caminhos a percorrer, visto sua tradição de um ensino historicamente empirista.

\section{Compreendendo a formação crítico-reflexiva}

Historicamente, a criticidade surge da urgência de livrar massas humanas de manipulações e crenças que as mantinham acorrentadas por ideologias. Pensadores clamavam por criticidade, mas com discernimento e uso de critérios para julgamento, principalmente em situações político-sociais. O senso crítico permite avançar nos pensamentos e acabar com passividades e atitudes de acatamento (MORAIS, 2000).

$\mathrm{Na}$ era da globalização, onde a tecnologia transcende fronteiras e dá acesso fácil a uma 
informação universal, o chamado período pósmodernidade chega requerendo algumas transformações e adequações para a inserção do trabalhador em um mundo competitivo e exigente. Com isso, a Educação Superior passa a ter a responsabilidade de formar e estimular profissionais com autonomia e curiosidade intelectual, que desenvolvam sua criatividade, que saibam agir, solucionar problemas, ampliar horizontes, um pensar crítico-reflexivo, participativo, um agente ativo nas transformações da sociedade; e não pessoas condenadas à conformidade e homogeneidade que assola $o$ mundo com tantas dúvidas e incertezas levando a uma preocupação degradante, desemprego por falta de mão de obra qualificada ou trabalhadores passivos, dependentes, acomodados, não críticos, não reflexivos, que nunca questionam e conseqüentemente o levam a exclusão social. Fato esse de interesse aos grupos que detém o poder, pois não terão dificuldades em manipular e dominar uma população não questionadora.

Sordi e Bagnato (1998, p. 86) relatam que "vários estudiosos apontam que para os futuros profissionais enfrentarem estas mudanças no mercado de trabalho, deverão possuir características e requisitos intelectuais básicos tais como autonomia, iniciativa, capacidade de resolução de problemas, criatividade, domínio da informática e de outras línguas".

A forma como o professor concebe a educação vai determinar a sua condução no processo ensino aprendizagem voltado para a formação de alunos comprometidos com sua realidade futura, como profissional crítico e reflexivo, no desenvolvimento de suas ações, buscando a construção de novos caminhos (TACLA, 2002).

Porém, existe uma carência na formação pedagógica do professor, que encontra dificuldades ao transmitir o que sabe para manter os alunos motivados. É importante ressaltar a colaboração de Masetto (2003, p. 35-37) com relação ao processo ensino-aprendizagem: os processos de ensino e aprendizagem são distintos, porém complementares. A ênfase que se coloca num ou noutro, fará com que os resultados da integração ou correlação dos dois processos sejam completamente diferentes. $\mathrm{Na}$ prática comum dos professores da educação superior, o que muitas vezes prevalece na atuação docente é o processo de ensino, no qual o professor "ensina" aos alunos que "não sabem" e estes reproduzem as informações recebidas nas provas ou nos exames buscando sua aprovação. De modo geral, até hoje, a docência universitária colocou sua ênfase no processo de ensino, com a organização curricular fechada e estanque; disciplinas conteudísticas referentes aos assuntos técnicos e profissionalizantes dos cursos; pouca abertura as outras áreas do conhecimento, a interdisciplinaridade, temas transversais e pouco incentivo a pesquisa na graduação. Neste cenário, o professor é o centro do processo e se pergunta: 0 que acho importante ensinar? Como gosto ou prefiro ensinar? Como me é mais fácil ensinar?

Por outro lado, quando colocamos a ênfase no aprender, todas as atividades estarão centradas no aprendiz; em suas capacidades, possibilidades, necessidades, oportunidades e condições para que aprenda. Neste caso, no processo de aprendizagem, as preocupações do professor se voltam para o que o aluno precisa aprender para se formar como um profissional cidadão; como o aluno aprenderá e fixará melhor; que técnicas favorecerão a sua aprendizagem e, como será feita a avaliação, de forma que o incentive a aprender.

Enfatiza-se, portanto, um processo de crescimento e desenvolvimento de uma pessoa em sua totalidade, contemplando quatro grandes áreas: a do conhecimento, a do afetivoemocional, a de habilidades e a atitudes ou 
valores. Ainda de Masetto (2002), como fazer o aluno se interessar pelas aulas, aprender a pensar, produzir conhecimento, refletir criticamente, relacionar suas vivências com 0 processo de aprendizagem?

Daí, a importância e o objetivo máximo de nossa docência deve ser a aprendizagem de nossos alunos, donde o professor precisa ter clareza do significado de aprender; seus princípios, modos, eficácia, fixação do saber.

E para ser um bom professor Freire (1996, p. 86) nos coloca:

Neste sentido, o bom professor é o que consegue, enquanto fala, trazer 0 aluno até a intimidade do movimento de seu pensamento. Sua aula é assim um desafio e não uma 'cantiga de ninar'. Seus alunos cansam, não dormem. Cansam porque acompanham as idas e vindas de seu pensamento, surpreendem suas pausas, suas dúvidas, suas incertezas.

No processo de formação de um profissional crítico-reflexivo, precisamos entender o significado de reflexividade e criticidade, no desenvolvimento de nossas ações como professores da Educação Superior para os cursos que preconizam profissionais com perfil críticoreflexivo.

A reflexividade nos faz entender que:

é a capacidade de voltar sobre si mesmo, sobre as construções sociais, sobre as intenções, representações e estratégias de intervenção. Supõe a possibilidade. Ou melhor, a inevitabilidade de utilizar o conhecimento à medida que vai sendo produzido, para enriquecer e modificar não somente a realidade e suas representações, mas também as próprias intenções e o próprio processo de conhecer. (PÉREZ GÓMEZ apud LIBÂNEO, 2006, p. 56).

Em uma compreensão crítica-reflexiva, onde a principal meta é viabilizar a formação de um profissional que reflete na ação, problematiza, indaga, verbaliza, Garcia (1992) coloca que se devem criar condições de trabalho em equipe e colaboração entre professores e alunos, aplicação de estratégias de ensino capazes de levá-los a diferentes formas de reflexão, tais como: a introspecção, o exame, a indagação, a espontaneidade, a auto-análise.Ainda do autor, para desenvolver um ensino crítico-reflexivo é necessário desenvolver no aluno destrezas e atitudes necessárias à reflexão; ao professor são necessárias destrezas empíricas, analíticas, avaliativas, estratégicas, práticas e de comunicação.

De Domenico e Ide (2005, p. 512), valendo-se da contribuição de Perrenoud, colocam que:

A postura e a capacidade reflexiva, entretanto, permitem a construção de saberes, o remanejamento constante pelo afastamento do planejamento inicial; a descentralização dos procedimentos rotineiros, prontos; a apreciação de um erro; o desenvolvimento da capacidade de preparar o profissional para lidar com imprevistos; entre outras possibilidades.

Também para Vasconcellos (1996), no ensino crítico-reflexivo, é fundamental a mobilização para o conhecimento e sua construção, a elaboração e expressão da síntese do conhecimento; e este conhecimento só acontece quando se propiciam espaços para desenvolvê-los, quando se vivenciam práticas significativas em sala de aula, quando há possibilidades de relacionar o conhecimento e a 
educação com a realidade profissional, política, econômica e social.

Segundo Nóvoa (apud MADEIRA, 2006, p. 39), "a formação de professores pode ser norteada pelo seu desenvolvimento pessoal no sentido de estimular uma perspectiva crítica reflexiva, que the forneça os meios para um pensamento autônomo".

Ainda, do autor, são fundamentais três aspectos contemplados no processo de viabilização de uma formação de qualidade: o desenvolvimento pessoal do professor, mediante formação crítico-reflexiva; o desenvolvimento profissional, ou seja, produzir a profissão docente (identidade), a partir de questionamentos sobre a autonomia e profissionalismo do professor face ao controle administrativo e as regulações burocráticas do Estado; e o desenvolvimento organizacional, pois, as inovações não ocorrem sem que ocorram transformações na organização escolar (NÓVOA, 1995).

Para a formação de um professor críticoreflexivo, que é a figura facilitadora nesse processo, são exigidos alguns requisitos que segundo Freire (1996), como professor, é preciso na prática educativa ter respeito ao educando quanto a sua identidade, dignidade e autonomia exigindo de nós mesmos, uma reflexão crítica também da nossa prática, em um trabalho com 0 aluno e não voltado para o próprio professor.

Portanto, a compreensão de reflexão crítica envolve os seguintes aspectos : a prática crítico-reflexiva ou progressiva é conseqüência da obrigatoriedade de conteúdos/saberes fundamentais no processo de formação do professor; o ensino exige reflexão crítica sobre a prática, implicante no pensar certo, portanto, dinâmico e dialético; e, a reflexão sobre a prática como uma exigência de interseção teoria/prática (FREIRE, 1996).

Tardif (2002) nos alerta para o fato de que, a formação dos professores não dá conta das necessidades do cotidiano escolar. Por essa razão, propõe uma mudança radical nas concepções e nas práticas de formação, considerando os professores como sujeitos do conhecimento, colaboradores e copesquisadores, produzindo pesquisas não só sobre o ensino, mas para o ensino, de forma que os professores se apropriem de um discurso e de uma linguagem objetiva da profissão e de uma prática pedagógica reflexiva.

Complementando, ressaltando a importância da formação continuada, se constituindo como:

[...] marcas mais evidentes
do processo de formação
contínua dos/as
professores/as
transparecem na sua prática
pedagógica, caracterizada
por uma ação docente mais
reflexiva, mais empática,
responsiva e inovadora.
Uma prática que envolve (e
requer) mudanças
frequentes. Mudanças,
principalmente cognitivas,
que conferem ada ada de
professor/a, ao lado do
outros atributos, segurança
pessoal e pedagógica,
aliada a uma auto-imagem
positiva. (LIMA apud
TELES, 2010, p. 39).

\section{CONSIDERAÇÕES FINAIS}

Sabemos que hoje, um dos grandes desafios da Educação Superior, será o de formar profissionais com um perfil crítico-reflexivo, com vistas ao desenvolvimento da autonomia e a práticas emancipatórias. Para tanto, precisamos pensar em mudanças de paradigmas; de professores, que como profissionais formadores de opinião, estejam preparados para refletirem sobre suas ações, tomarem decisões, serem críticos e criativos diante dos desafios das atividades profissionais do dia a dia.

Por outro lado, o processo educativo ainda é permeado pelo tradicionalismo, com a 
transmissão de saberes previamente construídos e sistematizados.

A realidade das Instituições formadoras de Educação Superior, mesmo na perspectiva de uma formação crítico-reflexiva, ainda tem muitos caminhos a percorrer, visto sua tradição de um ensino historicamente empirista.

Masetto (2003, p. 28), descata:

[...] em geral, nos
preocupamos com que
nossos alunos aprendam
conhecimentos,
informações,
desenvolvam
intelectualmente, pouco
nos importando com o
desenvolvimento de suas
habilidades humanas e
profissionais e de seus
valores de profissionais e
cidadãos comprometidos
com os problemas e a
evolução de sua
sociedade.

Ainda do autor, é ressaltada a importância do aluno desenvolver uma reflexão crítica, que lhe permitirá conhecer teorias e pontos de vista diferentes, dilogar sobre valores, alternativas para o exercício da profissão, analisar as perspectivas do mundo social e político.

Nesta mesma linha de pensamento, Pimentel (2005, p. 19) diz que:

[...] o que os alunos valorizam mesmo, mais do que o ensino em sala de aula, são as aprendizagens que realizam na vida universitária como um todo. [...] Atribuem a ela seu crescimento amadurecimento humanos, seu desenvolvimento social e cultural, sua independência intelectual e a aquisição de qualidades consideradas fundamentais para a vida profissional: assumir responsabilidades, tomar iniciativas, ajuizar criticamente, comprometerse socialmente.
Portanto, para a formação de alunos e professores com senso crítico e indagadores, refletindo sobre as mudanças para este novo perfil, é preciso que se façam inovações para as universidades; que, como bem coloca Moran (2000), ultrapassem os limites da previsibilidade e da burocracia, tornando-se uma organização significativa, desafiadora, inovadora e empreendedora.

Concluindo, para que aconteça uma renovação da Instituição educativa, como tão bem colocado por Imbernón (2010), clama-se a necessidade de uma redefinição da profissão docente, que assuma novas competências profissionais no campo pedagógico, científico e cultural, ou seja, um profissional diferente.

Uma cultura crítica, leva professores juntamente com os alunos, a buscarem uma sociedade mais humana e justa bem como a estarem cientes da missão social que irão assumir profissionalmente.

\section{REFERÊNCIAS}

DE DOMENICO, E. B. L.; IDE, C. A. C. Estratégias apontadas pelos docentes para 0 desenvolvimento das competências nos diferentes níveis de formação superior em enfermagem. Rev. Bras. Enfermagem, v. 58, n. 5, p. 509-12, set./out., 2005. Disponível em: <http://www.scielo.br/scielo.php?script=sci arttext \&pid=S0034-71672005000500002\&lng=pt\&nr

$\mathrm{m}=\mathrm{iso}>$. Acesso em: 10 mar. 2011. http://dx.doi.org/10.1590/S0034-

71672005000500002

FREIRE, P. Pedagogia da autonomia: saberes necessários à prática educativa. São Paulo: Paz e Terra,1996.

FREITAS, L. C. Crítica da organização do trabalho pedagógico e da didática. Campinas: Papirus, 1995.

FRIGOTTO, G. Cidadania e formação técnico profissional: desafios neste fim de século. In: SILVA, L. H. et al. (org.). Novos mapas culturais, novas perspectivas educacionais. Porto Alegre: Sulina, 1996. p. 137-164.

GARCIA, C. M. A formação de professores: novas perspectivas baseadas na investigação sobre 0 
pensamento do professor. In: NOVOA, A. (org.). Os professores e a sua formação. Lisboa: Publ. Dom Quixote, 1992. p. 51-56.

HOFFMAN, J. Avaliação mediadora: uma prática em construção da pré-escola à universidade. 3.ed. Porto Alegre: Educação e Realidade, 1994.

IMBERNÓN, F. Formação docente e profissional: formar-se para a mudança e a incerteza. 8.ed. São Paulo: Cortez, 2010. (Coleção questões da nossa época; v. 14).

LIBÂNEO, J. C. Reflexividade e formação de professores: outra oscilação do pensamento pedagógico brasileiro? In: PIMENTA, S. G.; GHEDIN, E. (orgs.). Professor Reflexivo no Brasil: gênese e crítica de um conceito. 4.ed. São Paulo: Cortez, 2006. p. 53-79.

LITWIN, E. Variações sobre a arte de narrar na aula universitária. In: VEIGA, I. P. A.; CASTANHO, M. E. L. M. (orgs.). Pedagogia universitária: a aula em foco. 5.ed. Campinas: Papirus, 2000. p. 194.

MADEIRA, M. Z. A. A prática pedagógica das professoras do Curso de Enfermagem: revisitando a construção dos saberes docentes. 2006. 159 f. Dissertação (Mestrado em Educação) - Centro de Ciências da Educação, Universidade Federal do Piauí, Teresina.

MASETTO, M. T. Simples assim. Revista Ensino Superior, São Paulo, v. 44, n. 4, p. 3-6, maio 2002.

MASETTO, M. T. Competência pedagógica do professor universitário. São Paulo: Summus, 2003.

MORAIS, J. F. R. A criticidade como fundamento do humano. In: VEIGA, I. P. A.; CASTANHO, M. E. L. M. (orgs.). Pedagogia universitária: a aula em foco. 5.ed. Campinas: Papirus, 2000. p. 5174.

MORAN, J. M. Aprendizagem significativa. Disponível em: <www.eca.usp.br/prof/moran>. Acesso em: 03 mar. 2010.

NÓVOA, A. (org). Profissão professor. Portugal: Porto Editora, 1991.

NÓVOA, A. (org). Formação de professores e profissão docente. In: NÓVOA, A. (coord.). Os professores e sua formação. 2.ed. Lisboa: Dom Quixote, 1995.

PIMENTEL, M. G. O professor em construção. Campinas: Papirus, 2005.
SORDI, M. R. L; BAGNATO, M. H. S. Subsídios para uma formação profissional crítico-reflexiva na área da saúde: o desafio da virada do século. Rev. Latino-Am. Enfermagem, Ribeirão Preto, v. 6, n. 2, abr. 1998 . Disponível em: $<$ http://www.scielo.br/scielo.php?script=sci_arttext \&pid=S0104$11691998000200012 \&$ lng $=p t \& n r m=i s o>$. Acesso em: 20 jun. 2012.

http://dx.doi.org/10.1590/S010411691998000200012.

TACLA, M. T. G. M. Desenvolvendo o pensamento crítico em alunos de Enfermagem: uma experiência através da metodologia da problematização. Goiânia: AB, 2002.

TARDIF, M. Saberes docentes e formação profissional. Petrópolis, RJ: Vozes, 2002.

TELES, F. A. R. Formação docente na escola: perspectiva para práticas pedagógicas críticoreflexivas no ensino médio. Disponível em: <www.ufpi.br>. Acesso em: 26 mar. 2010.

VASCONCELLOS, C. S. Construção do conhecimento em sala de aula. 4.ed. São Paulo, 1996. (Cadernos Pedagógicos da Libertad, 2). 